\title{
Erratum to: Cover Crops for Sustainable Farming
}

\author{
Eric Justes
}

\section{Erratum to: \\ E. Justes (ed.), Cover Crops for Sustainable Farming, https://doi.org/10.1007/978-94-024-0986-4}

The original version of this book was published with incorrect author names for chapters 1, 2 and 3. It is corrected and updated as:

Chapter 1. Study Context and Methodology

Authors: Eric Justes, Julie Constantin, Caroline Dürr, Carole Hermon, Christine Le Bas, Catherine Mignolet, Isabelle Savini, and Olivier Réchauchère

Chapter 2. Main Lessons Drawn from the Analysis of the Literature

Authors: Eric Justes, Nicolas Beaudoin, Patrick Bertuzzi, Raphaël Charles, Julie Constantin, Carolyne Dür, Alexandre Joannon, Christine Le Bas, Bruno Mary, Françoise Montfort, Laurent Ruiz, Jean-Pierre Sarthou, Véronique Souchère, and Julien Tournebize

Chapter 3. Main Lessons Drawn from the Simulation Study

Authors: Eric Justes, Julie Constantin, Nicolas Beaudoin, Carolyne Dürr, Bruno Mary, and Laurent Ruiz

The original version of this book was published without a second sub-section in chapter 4. It is corrected and updated as:

4.2 Remaining Crucial Research Questions to be Explored

The updated online version of the original book can be found under https://doi.org/10.1007/978-94-024-0986-4_1

https://doi.org/10.1007/978-94-024-0986-4_2

https://doi.org/10.1007/978-94-024-0986-4_3

https://doi.org/10.1007/978-94-024-0986-4_4

https://doi.org/10.1007/978-94-024-0986-4 